\title{
CORRIGENDUM
}

\section{The nuclear receptor TR3 regulates mTORC1 signaling in lung cancer cells expressing wild-type p53}

S-O Lee, T Andey, U-H Jin, K Kim, M Singh and S Safe

Oncogene (2012) 31, 3310; doi:10.1038/onc.2012.184

Correction to: Oncogene (2012) 31, 3265-3276; doi:10.1038/ onc.2011.504; published online 14 November 2011

Since the publication of the above manuscript the authors have identified an error in the author list; the name of the fifth author was incorrectly presented. The corrected author list is shown above.

In addition to the funding sources mentioned in the paper, the authors also acknowledge the financial assistance provided by the National Center for Research Resources, the National Institute of Minority Health and Health Disparities of the National Institutes of Health and Department of Defense Institutional Research Award of USAMRMC, Department of Defense Congressionally Directed Medical Research Programs through Grant Numbers 8 G12 MD007582-28, 2 G12 RR003020 and BC103116, respectively. 